DE

M E D I C I N A

T R O P I C A L

$\mathrm{DE}$

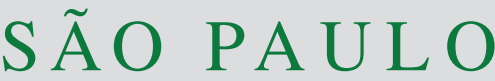

JOURNAL OF THE SÃO PAULO INSTITUTE OF TROPICAL MEDICINE

${ }^{1}$ Centro Paula Souza, ETEC Darcy Pereira de Moraes, Itapetininga, São Paulo, Brazil

2Universidade Estadual Paulista, Instituto de Biociências, Departamento de Parasitologia, Botucatu, São Paulo, Brazil

${ }^{3}$ Faculdades Integradas de Bauru, Bauru, São Paulo, Brazil

${ }^{4}$ Universidade do Sagrado Coração, Departmento de Ciências da Saúde, Bauru, São Paulo, Brazil

Correspondence to: Semíramis Guimarães

Universidade Estadual Paulista, Instituto de Biociências, Departamento de Parasitologia, Distrito de Rubião Junior, s/n, Caixa Postal 510, CEP 18618-970, Botucatu, SP, Brazil

E-mail: guimaraes.viana@unesp.br

Received: 17 June 2019

Accepted: 2 March 2020

\section{Genetic analysis of Giardia duodenalis isolates from children of low-income families living in an economically successful region in Southeastern Brazil}

\author{
Cláudia Rosana Trevisani Corrêa ${ }^{1}$, Ana Paula Oliveira-Arbex ${ }^{2,3}$, Érica Boarato \\ David $^{2,4}$, Semíramis Guimarães ${ }^{\left({ }^{2}\right.}$
}

\section{ABSTRACT}

Giardia duodenalis is one of the most important and widespread gastrointestinal parasites in the world. Despite its relevance as a causative agent of diarrhea, asymptomatic giardiasis occurs frequently, especially in low resources settings in which children are exposed to many risk factors. Based on microscopic examination and the polymerase chain reaction (PCR) amplification and sequencing of beta-giardin $(b g)$, triose phosphate isomerase (tpi) and glutamate dehydrogenase ( $\mathrm{gdh}$ ) genes, we assessed G. duodenalis occurrence and genetic diversity in isolates of children attending a daycare center and living in low income families, in an economically successful region. Considering both, microscopic examination and PCR/ sequencing methods, the overall prevalence of Giardia infection was $51.4 \%$, with the highest frequency in children aged $1-4$ years old $(\mathrm{p}<0.05)$. Genotyping of 50 isolates revealed that the assemblage A was found in $60 \%$ of the samples (30/50), followed by the assemblage B in $38 \%$ (19/50) and $2 \%$ of mixed-assemblage infections (1/50). At the sub-assemblage level, isolates genotyped as A were AII and among isolates B, BIII and BIV were identified. Both assemblages A and B were detected in children of all age groups, however assemblage A was more prevalent. The detection of anthroponotic assemblages and sub-assemblages (AII, BIII and BIV) reinforces human-to-human transmission, mainly in children of all age groups when they have not yet received toilet training, making them more vulnerable to infection.

KEYWORDS: Giardia duodenalis. Genetic diversity. Children. Daycare. Low income.

\section{INTRODUCTION}

Giardia duodenalis (syn. G. intestinalis, G. lamblia) is a common intestinal parasite infecting human populations worldwide. High infection rates of giardiasis have been reported in developing countries in which many groups and communities are at higher risk due to poverty, poor hygienic practices, lack of or limited access to adequate healthcare, safe drinking water and sanitation services ${ }^{1,2}$. In contrast, in developed areas, the prevalence of giardiasis is lower, and G. duodenalis is a frequent cause of epidemic waterborne diarrheal disease ${ }^{3}$.

Giardiasis has a range of clinical manifestations, from asymptomatic infections to a chronic diarrheal syndrome, malabsorption, and weight loss. However, asymptomatic giardiasis is the most frequent clinical presentation in developing countries. In these settings, children are frequently exposed to infection and many of them are malnourished and harbor a great burden of Giardia infection ${ }^{4}$. Nonetheless, based on new approaches to assess pathogen-specific diarrhea agents in these settings, the Giardia burden has not been associated to diarrhea in this population ${ }^{4}$. 
In view of genetic characteristics and the great variability of hosts, $G$. duodenalis isolates can be classified into at least eight assemblages $(\mathrm{A}-\mathrm{H})^{1,5}$. Among these genetic groups, assemblages $\mathrm{A}$ and $\mathrm{B}$ are considered to be potentially zoonotic, since they infect humans, as well as a wide range of mammals ${ }^{5}$. According to the multilocus genotyping of 18SrRNA, $g d h, t p i, b g$ followed by sequencing analysis, human isolates can later be placed in sub-assemblages AI, AII, BIII and BIV ${ }^{5}$. Molecular epidemiological surveys have provided insights into the genetic diversity of isolates infecting human populations in low-resource communities in which infection has been commonly reported in children ${ }^{6-9}$. Regardless of the clinical impact of endemic giardiasis, infected children are potential sources of cysts through which the infection is disseminated and transmitted to other children and adults in close contact, in the same way as observed in childcare environments ${ }^{8}$. Therefore, the context in which a target population is presented can provide information for a better understanding of the epidemiological significance of G. duodenalis infections. In the present study, we report the occurrence of Giardia infections and the genetic diversity of isolates from children attending a childcare center and living in low-income families of a successful socioeconomic region in São Paulo State, Brazil.

\section{MATERIALS AND METHODS}

\section{Study setting, population, sample collection and processing}

From March to September 2017, a coproparasitological survey was conducted in a public daycare and preschool center of Itapetininga, a municipality in the Southwestern region of Sao Paulo State, Brazil (233' $08^{\circ}$ 'S, 48 3'11' W). This city is located in a developed region and has a high Human Development Index (HDI=0.763), however some urban population groups live in pockets of poverty on the outskirts. The daycare enrolled in the study serves children under six years of age living in a district with access to basic services, such as safe drinking water, sanitation facilities, health care and education.

Epidemiological data (parents/legal guardians occupation and education level, household income, number of adults and children in the families, source of drinking water, sewage availability, latrine system, housing type, and contact with pets at home), aside from clinical information on symptoms related to intestinal parasitic infections (diarrhea, abdominal pain) were provided by parents/guardians in an interview during which a structured questionnaire was applied. Data on the gender and age of children were obtained directly from the school's registration system.

According to the daycare classrooms distribution, the participants were grouped by age according to the following categories: under 1 year of age, aged 1 to 4 years old and more than 4 years old. A single fecal sample was collected from 105 children under six years old and preserved in $2.5 \%$ potassium dichromate solution. In the laboratory, each sample was transferred to test tubes and washed three times with phosphate buffered saline ( $800 \mathrm{~g}$ for $3 \mathrm{~min}$ ) to remove the potassium dichromate. The sediment was used for the preparation of microscopic slides that were examined by light microscopy under x 100 and x 400 magnifications, to search for the presence of Giardia cysts and other intestinal parasites. Next, an aliquot of fecal sediment was processed using a zinc sulfate solution (1.18 specific gravity) to perform a flotation technique and samples were examined as previously described.

\section{Ethics statement}

All the procedures in the study were reviewed and approved by the Research Ethics Committees of the Botucatu Medical School, UNESP (protocol CAAE $\mathrm{N}^{\circ}$ 62265316.5.0000.5411). During informational meetings to present the research proposal, written informed consent was obtained from parents or legal guardians of the children.

\section{DNA extraction}

DNA was extracted from all the fecal samples (positive and negative to Giardia cysts). Prior to the extraction, $200 \mathrm{mg}$ of fecal sediments were subjected to three cycles of freezing and thawing as follows: two cycles of $5 \mathrm{~min}$ in liquid nitrogen and thawing in a water bath at $70{ }^{\circ} \mathrm{C}$, followed by one cycle of freezing in liquid nitrogen for $5 \mathrm{~min}$ and thawing at $95{ }^{\circ} \mathrm{C}$ for $5 \mathrm{~min}$. The resulting crude DNA was then used to obtain purified DNA using the QIAamp ${ }^{\circledast}$ Fast DNA Stool Mini Kit (Qiagen, Hilden, Germany) following the manufacturer's instructions. The final DNA was eluted in $200 \mu \mathrm{L}$ of the elution buffer and divided into aliquots stored at $-20^{\circ} \mathrm{C}$ until further analysis.

\section{Molecular detection, sequencing and phylogenetic analysis}

Molecular analysis was carried out by amplifying three gene loci including the triose phosphate isomerase (tpi), glutamate dehydrogenase $(g d h)$ and beta-giardin $(b g)$. For all the three genes, a $50 \mu \mathrm{L}$ PCR mix containing $5 \mu \mathrm{L}$ of DNA template, $1 \mu \mathrm{L}(1 \mu \mathrm{M})$ (of each primer) and $25 \mu \mathrm{L}$ 
of the Taq DNA Polymerase Master Mix RED from the 2.0 x Master Mix containing $2.0 \mathrm{mM} \mathrm{MgCl}{ }_{2}$ were prepared (Ampliqon A/S, Stenhuggervej, Denmark).

A nested PCR was used to amplify a 530-bp region of the tpi fragment using the primers AL3543 (5'-AAATIATGCCTGCTCGTCG-3') and AL3546 (5'-CAAACCTTITCCGCAAACC-3') in the first round and the primers AL3544 (5'-CCCTTCATCGGIGGTAACTT-3') and AL3545 (5'-GTGGCCACCACICCCGTGCC-3') in the second round of amplification ${ }^{10}$. The cycling conditions for both rounds were as follows: initial denaturation at $95{ }^{\circ} \mathrm{C}$ for $45 \mathrm{~s}$, followed by 35 cycles of $94{ }^{\circ} \mathrm{C}$ for $45 \mathrm{~s}, 59^{\circ} \mathrm{C}$ for $45 \mathrm{~s}, 72{ }^{\circ} \mathrm{C}$ for $45 \mathrm{~s}$, and a final extension step at $72{ }^{\circ} \mathrm{C}$ for $10 \mathrm{~min}$.

For the $g d h$ amplification, a semi-nested PCR amplified a 432-bp fragment with the primers GDHeF (5'-TCAACGTYAAYCGYGGYTTCCGT-3') and GDHiR (5'-GTTRTCCTTGCACATCTCC-3') in the first round and the primers GDHiF (5'-CAGTACAACTCYGCTCTCGG-3') and the same GDHiR in the second round of amplification ${ }^{11}$. The reactions were performed in a total of 34 cycles using the following conditions: $1^{\text {st }} \mathrm{PCR}\left(95^{\circ} \mathrm{C}\right.$ for $30 \mathrm{~s}, 58^{\circ} \mathrm{C}$ for $30 \mathrm{~s}$ and $72{ }^{\circ} \mathrm{C}$ for $\left.30 \mathrm{~s}\right)$ and semi- nested PCR $\left(95^{\circ} \mathrm{C}\right.$ for $30 \mathrm{~s}, 59^{\circ} \mathrm{C}$ for $30 \mathrm{~s}$ and $72{ }^{\circ} \mathrm{C}$ for $30 \mathrm{~s}$ ). Reactions began with an initial hot start step $\left(95^{\circ} \mathrm{C}\right.$ for $\left.1 \mathrm{~min}\right)$ and a final extension for 4 min at $72{ }^{\circ} \mathrm{C}$.

A partial sequence of the $b g$ gene (approximately 511-bp) was amplified in a nested-PCR with the primers G7 (5'-AAGCCCGACGACCTCACCCGCAGTGC-3') and G759 (5'-GAGGCCGCCCTGGATCTTCGAGACGAC-3') in the first round, and BG511 F (5'-GAACGAACGAGATCGAGGTCCG-3') and BG511R (5'-CTCGACGAGCTTCGTGTT-3') in the second round of amplification ${ }^{12}$. The reactions were performed in a total of 35 cycles using the following conditions: $1^{\text {st }} \mathrm{PCR}\left(95^{\circ} \mathrm{C}\right.$ for $30 \mathrm{~s}, 65^{\circ} \mathrm{C}$ for $30 \mathrm{~s}$ and $72{ }^{\circ} \mathrm{C}$ for $60 \mathrm{~s}$ ) and nested-PCR $\left(95^{\circ} \mathrm{C}\right.$ for $30 \mathrm{~s}, 55^{\circ} \mathrm{C}$ for $30 \mathrm{~s}$ and $72^{\circ} \mathrm{C}$ for $60 \mathrm{~s}$ ). Reactions began with an initial hot start step $\left(95^{\circ} \mathrm{C}\right.$ for $\left.15 \mathrm{~min}\right)$ and a final extension for $7 \mathrm{~min}$ at $72{ }^{\circ} \mathrm{C}$.

In all the PCR assays, DNA from axenic Giardia culture was used as the positive control and negative controls were included. The amplification products were analyzed by horizontal electrophoresis in $1.5 \%$ agarose gels stained with ethidium bromide

The amplified DNA fragments were purified using spin columns (QIAquick PCR purification kit, QIAGEN, Hilden, Germany) and both strands of the amplification products were processed in an ABI 3730 sequencer (Appplied Biosystems, Thermo Fisher Scientific, Waltham, MA, USA), using the same set of primers as in the PCR assays. The resulting nucleotide sequences were aligned with each other and reference sequences were downloaded from GenBank using the Clustal X2 ${ }^{13}$ software and the assemblages and sub-assemblages at each locus were identified by the BLAST software (National Center for Biotechnology Information, U.S. National Library of Medicine, Bethesda, Maryland, USA). For the phylogenetic analysis, sequence alignment was performed using two different probabilistic methods: the maximum likelihood (ML) analysis performed with the Phyml v.3.1 ${ }^{14}$, and the Bayesian inference analysis carried out using the Mr Bayes v3.1.215. Both analyses were performed in the Geneious Prime 2019.2.3 software (Biomatters, Ltd, Auckland, New Zealand). Representative isolates obtained in the present study were deposited in GenBank (accession No MK955231-MK955235, MK975890-MK97589).

\section{Statistical analysis}

The Chi-square test or Fisher's exact test were applied to verify associations between Giardia infections with some epidemiological and clinical variables. Statistical analyses were performed using the SAS 9.3 and the significance level was set at $P<0.05$.

\section{RESULTS}

\section{Study population and occurrence of $G$. duodenalis}

From a total of 121 children, 105 returned a stool sample for parasites investigation and 96 completed the socioeconomic questionnaire (Table 1). During the survey, all the staff members in the daycare were asked to provide a stool sample, but none agreed to participate in the survey.

Among the 105 children included in this survey, $60 \%$ (63/105) were males and 40\% (42/105) were females (Table 1). The mean age was $3.6(\mathrm{SD} \pm 1.4)$ years and $4.8 \%(5 / 105)$ were under 1 year of age, $46.6 \%(49 / 105)$ were in the age group 1-4 years and $48.6 \%(51 / 105)$ in the group of more than 4 years old (4.1 to 5.9 years old). Based on the questionnaires (Table 1), data revealed that approximately $97 \%$ of children live in houses with public water supply, sewerage system and garbage collection. Most children (63.5\%) belong to families with monthly income varying between $\leq 0.5$ to 1.6 of the current Brazilian minimum wage (937 BRL/Month). In addition, $72 \%$ of children belong to families with more than three members (4-6 individuals) and in $87 \%$ of them, the parents and/or guardians had at least five to 11 years of formal education. Domestic animals were present in 73\% (70/96) of the houses and dogs were the animals in 59\% (57/96) of the houses. 
Table 1 - G. duodenalis infections and sociodemographic characteristics in children attending a daycare center in Southeastern Brazil.

\begin{tabular}{|c|c|c|c|c|}
\hline \multirow[b]{2}{*}{ Variable1 } & \multicolumn{3}{|c|}{ Giardia infection $^{2}$} & \multirow[b]{2}{*}{$P$-value } \\
\hline & $\begin{array}{c}\text { Yes } \\
\text { N (\%) }\end{array}$ & $\begin{array}{c}\text { No } \\
N(\%)\end{array}$ & $\begin{array}{c}\text { Total } \\
\mathrm{N}\end{array}$ & \\
\hline \multicolumn{5}{|l|}{ Gender } \\
\hline Male & $33(61.1)$ & $30(58.8)$ & 63 & \multirow{2}{*}{0.84} \\
\hline Female & $21(38.9)$ & $21(41.2)$ & 42 & \\
\hline \multicolumn{5}{|l|}{ Age group (years) } \\
\hline$<1$ & $05(9.2)$ & 0 & 05 & \multirow{3}{*}{0.001} \\
\hline $1-4$ & $33(61.2)$ & $16(31.4)$ & 49 & \\
\hline$>4$ & $16(29.6)$ & $35(68.6)$ & 51 & \\
\hline \multicolumn{5}{|l|}{ Source of drinking water } \\
\hline Treated & 47 (95.9) & $46(97.9)$ & 93 & \multirow{2}{*}{1.00} \\
\hline Untreated & $02(4.1)$ & $01(2.13)$ & 03 & \\
\hline \multicolumn{5}{|c|}{ Drinking water consumption } \\
\hline Filtered or boiled & $18(36.7)$ & $09(19.1)$ & 27 & \multirow{2}{*}{0.09} \\
\hline Directly from the tap & $31(63.3)$ & $38(80.9)$ & 69 & \\
\hline \multicolumn{5}{|l|}{ Sewerage system } \\
\hline Yes & $47(95.9)$ & $46(97.9)$ & 93 & \multirow{2}{*}{1.00} \\
\hline No & $02(4.1)$ & $01(2.1)$ & 03 & \\
\hline \multicolumn{5}{|l|}{ Toilet at home } \\
\hline Yes & $48(97.9)$ & $46(97.9)$ & 94 & \multirow{2}{*}{1.00} \\
\hline No & $01(2.1)$ & $1(2.1)$ & 02 & \\
\hline \multicolumn{5}{|l|}{ Animals at home ${ }^{3}$} \\
\hline Yes & $36(73.5)$ & $34(72.3)$ & 70 & \multirow{2}{*}{0.94} \\
\hline No & $13(26.5)$ & $13(27.7)$ & 26 & \\
\hline \multicolumn{5}{|c|}{ Presence of dogs at home } \\
\hline Yes & $31(63.3)$ & $26(55.3)$ & 57 & \multirow{2}{*}{0.42} \\
\hline No & $18(36.7)$ & $21(44.7)$ & 39 & \\
\hline \multicolumn{5}{|c|}{ Parents/guardians' education (years) } \\
\hline $1-4$ & $02(4.1)$ & $04(8.5)$ & 06 & \multirow{4}{*}{1.00} \\
\hline $5-8$ & $14(28.5)$ & $14(29.8)$ & 28 & \\
\hline $9-11$ & $29(59.2)$ & $27(57.4)$ & 56 & \\
\hline$>11$ & $04(8.2)$ & $02(4.3)$ & 06 & \\
\hline \multicolumn{5}{|l|}{ Family income ${ }^{4}$} \\
\hline$<0.5 \mathrm{MW}$ & $05(10.2)$ & $06(12.7)$ & 11 & \multirow{4}{*}{0.93} \\
\hline $0.5-1.1 \mathrm{MW}$ & $13(26.5)$ & 13(27.7) & 26 & \\
\hline 1.2-1.6 MW & $11(22.5)$ & $13(27.7)$ & 24 & \\
\hline$>1.6 \mathrm{MW}$ & $20(40.8)$ & $15(31.9)$ & 35 & \\
\hline \multicolumn{5}{|l|}{ Family size (members) } \\
\hline $2-3$ & $13(26.5)$ & $14(29.8)$ & 27 & \multirow{3}{*}{0.99} \\
\hline $3-6$ & $30(61.2)$ & $30(63.8)$ & 60 & \\
\hline$>6$ & $06(12.3)$ & $03(6.4)$ & 09 & \\
\hline
\end{tabular}

${ }^{1}$ The s ample size was 96 children for all of the variables, excepting for gender and age $(n=105) .{ }^{2}$ Giardia detection by microscopy and/or PCR/sequencing. ${ }^{3}$ Companion animals were dogs, cats, chickens and pigs. ${ }^{4} \mathrm{MW}=$ Minimum Wage/month (at the time of the study, the MWwas 937 BRL; i.e., approximately US\$293). 
After the sedimentation and flotation procedures, the microscopic examination revealed intestinal parasites in $36.2 \%(38 / 105)$ of the stool samples tested and, $7.6 \%$ (8/105) of the positive samples were found to contain Giardia cysts. Other intestinal parasites could also be found, and their frequencies were: Blastocystis 15.2\% (16/105), Entamoeba coli and Endolimax nana with 11.4\% (12/105) each, Trichuris trichiura and Ascaris lumbricoides with $1 \%(1 / 105)$ each.

All the 105 fecal samples (8 Giardia-positive samples and 97 Giardia-negative samples by microscopy) were submitted to PCR reactions and a positive result was considered when at least one of the three loci assessed ( $g d h, t p i$ and $b g$ ) was successfully amplified and sequenced. From a total of 50 samples (three microscopy- positive and 47 microscopy-negative samples) that tested positive by at least one of the PCR assays, 43 showed products for only one gene, 6 for two genes and only one for all the three genes analyzed. In total, 58 amplicons were successfully sequenced, confirming the infections by $G$. duodenalis. The PCR amplification rates were $83 \%$ (48/58) at $g d h$ locus versus $10 \%(6 / 58)$ and $7 \%(4 / 58)$ at $b g$ and tpi loci, respectively (Table 2).

Table 2 - Distribution of G. duodenalis assemblages among the 50 isolates obtained from children and the genotyping carried out by PCR/sequencing of the gdh, bg and tpi loci.

\begin{tabular}{lcccc}
\hline \multirow{2}{*}{ Locus } & \multicolumn{3}{c}{ Assemblages } & \multirow{2}{*}{$\begin{array}{c}\text { Total } \\
\text { amplicons }\end{array}$} \\
\cline { 2 - 4 } & $\mathrm{A}$ & $\mathrm{B}$ & $\mathrm{A}+\mathrm{B}$ & $\mathbf{4}$ \\
\hline gdh & 29 & 18 & 1 & 48 \\
tpi & 2 & 3 & 1 & 6 \\
\hline Combined results & 30 & 19 & 1 & $\mathbf{5 0}$ \\
\hline
\end{tabular}

The frequency of Giardia infections was lower $(7.6 \%$, $8 / 105)$ by microscopy than by PCR/sequencing $(47.6 \%$, 50/105) Considering both methods, the overall rate of Giardia infections was 51.4\% (46 PCR-positive samples, 4 microscopy/PCR-positive samples and 4 microscopypositive samples). Out of the 54 Giardia-positive samples, coinfection with other parasites was found in 26 (9 cases with Blastocystis, 9 cases with Entamoeba coli, 7 cases with Endolimax nana, and 1 case with Trichuris trichiura). According to information obtained from parents/guardians, all of the children were considered asymptomatic, since no episodes of diarrhea and no other gastrointestinal symptoms were reported two months prior to the stool sample collection and during the survey. Among all the socioeconomic and demographic variables analyzed
(Table 1), the age was the only one associated with Giardia infection as the frequency of infection was significantly higher in children in age group of 1-4 years $(p=0.001)$.

\section{Molecular characterization of $G$. duodenalis isolates}

Among the 50 samples successfully genotyped, five $(10 \%)$ were obtained from children under 1 year of age, 32 (64\%) and 13 (26\%) from children aged 1 to 4 years and more than 4 years old, respectively (Figure 1). This distribution is in Figure 1. The alignment analysis identified only isolates classified as assemblages A and B, most of them obtained for the amplification of the $g d h$ locus, especially the former group (Figure 1, Table 2). Forty-nine isolates were unambiguously identified as A or B without inconsistencies in the separation of groups. An assemblage discordance was observed in only one specimen typed as A and B at the $g d h$ and $b g$ loci, respectively (Table 2). Thus, assemblage $\mathrm{A}$ was found in $60 \%$ of the samples (30/50), followed by $38 \%$ of assemblage B (19/50) and $2 \%$ of mixed-assemblage infections (1/50). Assemblages A and B were detected in children of all ages and classes, however in the classes in which the infection was most prevalent, assemblage A was predominant. No statistical correlation between assemblage and distribution by age was observed, as much as no relationships with sociodemographic variables were found. In addition, no association was established between assemblages and the children clinical status, since at the time of the study, all the infected children were asymptomatic.

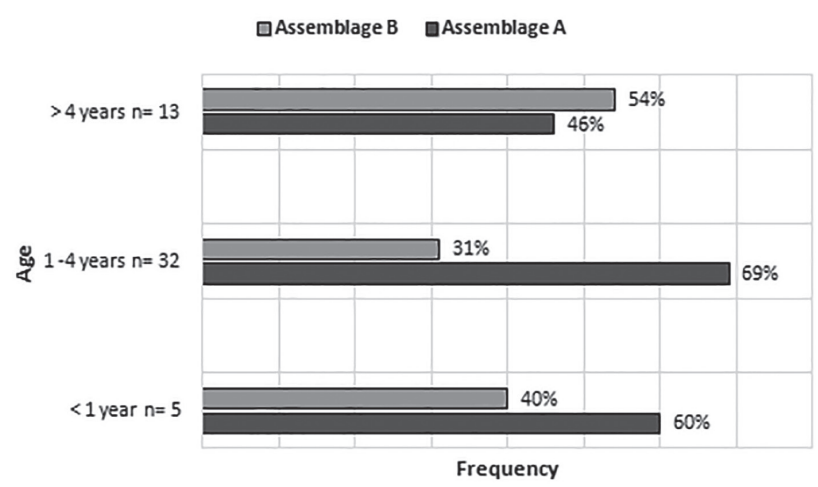

Figure 1 - Frequency of G. duodenalis assemblages according to the daycare classes.

Based on the phylogenetic analysis, 27 assemblage A sequences were assigned as sub-assemblage AII and four could not be identified to the sub-assemblage level and they were referred as assemblage A only. Concerning the assemblage B, 12 sequences were classified as subassemblage BIV, three as BIII, while four sequences did not allow the sub-assemblage assignment of isolates and were referred just as assemblage B. 
The nucleotide sequences determined in this study were compared to homologous previously identified sequences and 46 representative isolates (36 at $g d h, 6$ at bg and 4 at tpi) were included in the phylogenetic tree (Figures 2 and 3). Comparative analysis of isolates using $g d h$, tpi and $b g$ sequences showed that the isolates were distributed in two distinct groups (A and B), as mentioned above. In general, most of the sequences obtained in the present study were not $100 \%$ identical to publicly available DNA sequences, neither with each other. The consensus analysis revealed high to moderate identity ranging from $80-99.7 \%$ (Figures 2 and 3). Phylogenetic trees demonstrated the grouping of isolates in two clades corresponding to assemblages A and B (Figures 2 and 3). However, some isolates assigned as assemblage A showed higher variability (Figure 2).

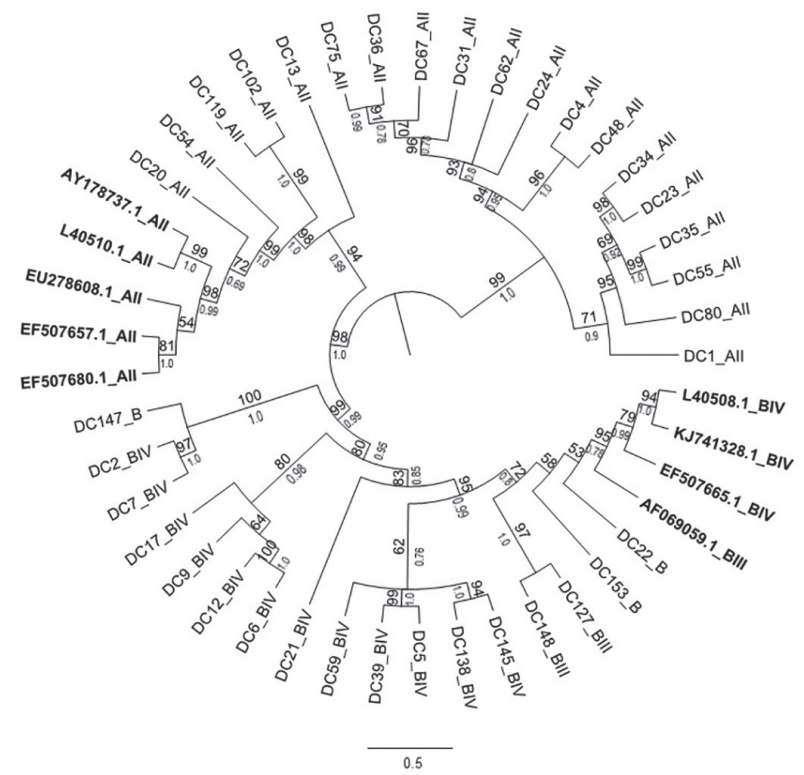

Figure 2 - Maximum likelihood (ML) and Bayesian inference (BI) reconstruction tree of $G$. duodenalis based on the nucleotide sequences of $g d h$ obtained in this study compared to reference sequences of known assemblages from GenBank (marked in bold). The numbers of the branches above correspond to the bootstrap values (only values above $50 \%$ are shown) and below are the posterior probabilities ( $\geq 0.5$ are highlighted).

Among the assemblage A sequences assigned at the gdh locus, only one isolate (DC54) was 100\% and $99.7 \%$ identical to the AII reference sequences EU278608 and L40510, respectively. In addition, this same isolate has also shown high similarity (99.7\%) with the sequence KT334235, a Brazilian human-derived isolate that was also retrieved from a child who attended a daycare center ${ }^{8}$. Other isolates (DC13, DC20, DC102 and DC119) demonstrated a similarity of 92-99.4\% with reference sequences (Figure 2). Moreover, the remaining isolates were more closely related

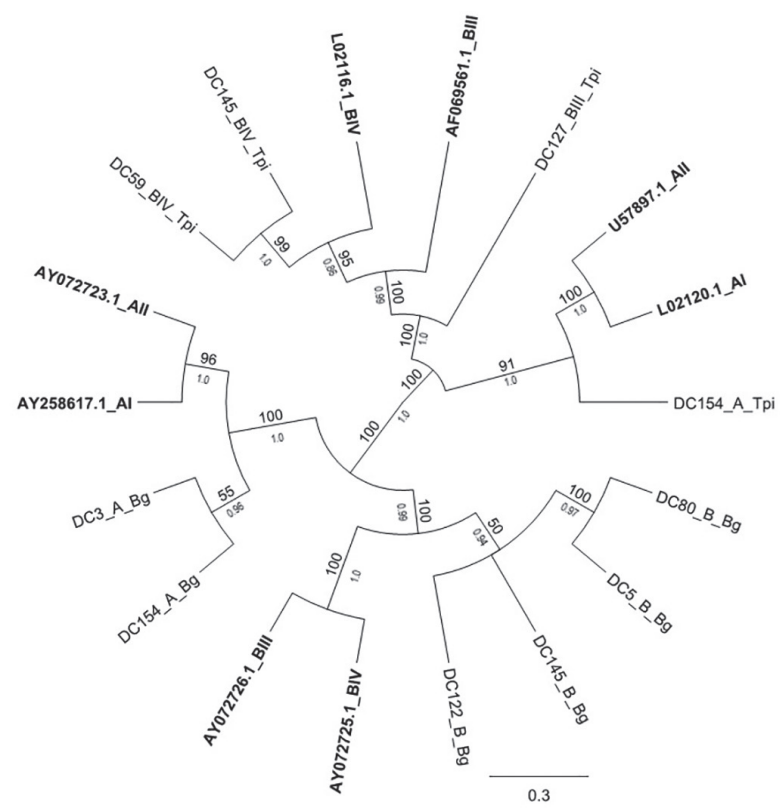

Figure 3 - Maximum likelihood (ML) and Bayesian inference (BI) reconstruction tree of $G$. duodenalis based on the nucleotide sequences of $b g$ and tpi obtained in this study compared to reference sequences of known assemblages from GenBank (marked in bold). The numbers of the branches above correspond to the bootstrap values (only values above $50 \%$ are shown) and below are the posterior probabilities ( $\geq 0.5$ are highlighted).

to each other than to the reference sequences. Among the isolates identified as assemblage B, none of them was $100 \%$ identical to the reference sequences, even though they displayed $80-98.7 \%$ identity with them (Figure 2). In this study, two isolates assigned as BIII (DC127 and DC148) were $96 \%$ identical to the reference AF069059, while the BIV isolates DC5, DC39, DC59, DC138 and DC145 were 97\% similar to the reference L40508. These same isolates were $99-99.7 \%$ identical to each other.

For $b g$ and $t p i$ loci, few nucleotide sequences were obtained and analyzed (Figure 3). At the $b g$ gene locus, both assemblage A sequences DC3 and DC154 showed 99.8\% identity with the AII reference sequence AY072724. The sequences DC5, DC80 and DC122 identified as assemblage B showed higher similarity (97.7\% to $98.9 \%$ ) with the reference AY072725, while DC145 was $100 \%$ identical to the reference EU274397. Sequences DC5 and DC122 were $99 \%$ identical to the references and $100 \%$ identical to each other. At $t p i$ locus, the only sample classified as an assemblage A isolate (DC154) showed 97\% similarity with the reference sequence EU781027. Both isolates DC59 and DC145 identified as assemblage B were $99.8 \%$ similar to BIV reference sequence (AF069561), while the isolate DC127 showed $90 \%$ identity with the BIII reference AF069561. 


\section{DISCUSSION}

Despite numerous community prevalence studies, epidemiology of giardiasis remains complex and several issues still need clarification. In the present study, the overall prevalence of Giardia infections among children under six years of age who attended a public daycare was $51.4 \%$ (54/105). This rate was reached only after PCR/ sequencing, considering that based on microscopy, Giardia infection was found in only $7.6 \%(8 / 105)$ of the children. This frequency was lower than those recently reported in daycare and preschool children living in communities of São Paulo State, some of them placed in regions near the study area ${ }^{8,16,17}$. Recently, the examination of one fecal sample has revealed Giardia infection rates ranging from $2.7 \%$ to $11 \%$ in children of preschool age in some surveys worldwide ${ }^{18-21}$ including Brazil ${ }^{22-25}$. Even when the diagnosis is based on the examination of three stool samples, the studies did not report much higher prevalence rates ${ }^{8,9,16,17}$. It is important to address that low-density infections may be a possible cause for false-negative results by microscopy examination. Nowadays, we believe that a plausible reason for this is the common practice of clinicians and/or parents to empirically treat children for intestinal parasites, at least once a year. This practice has been frequent, mainly in resource-poor communities in which the individuals are at higher risk of infection. However, accurate diagnosis of intestinal parasites in children is imperative considering that the assessment on the impact of infections may strengthen public health initiatives.

Regarding some epidemiological aspects, no association was found between the prevalence of Giardia infection and sociodemographic variables, excepting for the frequency of infection that was significantly higher in younger children, aged 1 to 4 years, as previously reported ${ }^{8,26,27}$. This fact has been reported and discussed over the years considering that children from one year old become mobile, but they are not yet toilet trained, increasing the proximity of people and reinforcing the possibility of interpersonal transmission to a more susceptible and exposed group ${ }^{28}$.

The genetic diversity of $G$. duodenalis was analyzed by sequencing of $g d h, b g$ and $t p i$ loci. Specific amplification differently performed at the three loci found that the $g d h$ locus reached the highest amplification rate $(96 \%)$, followed by $b g$ locus (12\%) and tpi locus (8\%). This is not an uncommon situation as the variability of PCR amplification success directed to different target genes has been recently discussed ${ }^{29}$. Among the most commonly used markers for Giardia typing, tpi has been considered the most variable locus showing a wide amplification spectrum ${ }^{1}$. However, higher $g d h$ gene amplification rates have been reported ${ }^{30-32}$.
The use of these single-copy genes reaches a much less and variable amplification rates, however the need for sub-genotype information lead to the use of less successful single-copy genes as they provide a more discriminating genetic variation ${ }^{29}$. In addition, according to Broglia et al. ${ }^{33}$, as these markers are all single-copy genes, the different amplification rates could not be explained by differences in target copy number. However, these authors emphasize that the presence of mismatches between the genomic sequences and the primers used in the PCR, may result in a marked reduction or even a lack of amplification of the target gene.

Sequencing analysis showed that all G. duodenalis positive cases were associated to assemblages A or B infections, with the predominance of the former group. Thus, assemblage A was found in $60 \%$ of the specimens (30/50), followed by $38 \%$ of assemblage B (19/50) and 2\% of mixed-assemblage infections (1/50). The occurrence of assemblages A and B is not surprising considering that to date, these groups have been frequently found in humans and animals infections worldwide ${ }^{1,34}$. The predominance of assemblage A corroborates the results of other studies in Brazil ${ }^{6,25,35}$, Malaysia ${ }^{36}$, Ethiopia ${ }^{37}$ and Slovakia ${ }^{20}$. In contrast, a higher prevalence of assemblage B has been reported in children in Brazil ${ }^{8,38}$ and in other countries ${ }^{39,40}$. On the other hand, some reports have demonstrated similar prevalences of isolates $A$ and $\mathrm{B}^{9,16}$. Taking into account the proportion of assemblages A and B reported globally, the molecular analysis of more than 2,800 isolates indicate that assemblage B (approximately58\%) has a higher prevalence than assemblage A (approximately $37 \%)^{34}$. However, in Latin America, the proportion of human infections by assemblages A and B does not differ markedly ${ }^{34}$. It is possible that the relative proportion of assemblage A with respect to assemblage B infections varies according to both, time and space ${ }^{41}$.

The occurrence of infections caused by mixed assemblages is not a rare finding, however in our study, only one specimen showed a discordant genotype result at $g d h$ and tpi loci. According to Ryan and Cacciò ${ }^{34}$, this inconsistency can be attributed to two possibilities: (1) mixed assemblage infections in a single fecal sample coupled with the preferential amplification of one assemblage at one locus and of another assemblage at another locus or (2) recombination between assemblages. However, a discordant typing seems to be more related to mixed infections, mainly in infected individuals living in low-income areas, where the prevalence of mixed infections was higher (5.2\%) than in developed ones $(3.2 \%)^{34}$.

Regarding the subtyping, within assemblage A, only the sub-assemblage AII was identified, while in assemblage B, BIII and BIV sub-assemblages were detected in the studied 
population. Subtyping studies of $G$. duodenalis isolates worldwide have shown that humans are more commonly infected with sub-assemblages AII, BIII and BIV ${ }^{1,34}$. Our results are similar to the ones of other investigations in which the detection of anthroponotic assemblages and subassemblages (AII, BIII and BIV) led to the conclusion that humans are a potential source of infection ${ }^{42,43}$. In the context of childcare institutions, the circulation of AII and B isolates (BIII and BIV) reinforces the relevance and possibility of person-to-person transmission in environments where young children without personal hygiene habits are in frequent and close contact with others. The phylogenetic analysis revealed some genetic variations within the nucleotide sequences of both, assemblages A and B isolates. Thus, as previously commented, most of the sequences obtained in the present study did not show a perfect identity with those previously described, neither with each other. A high degree of polymorphism has been noticed within isolates A and B from humans, especially those assigned as assemblage $\mathrm{B}^{1}$. The greater genetic diversity observed in human sequences in this study could indicate the possibility of different sources of infection for children living in this area.

Up to now, the role of genetic variability of $G$. duodenalis in the clinical presentation of giardiasis has been investigated in children, however the conclusions are still very controversial since assemblages A and B have been associated with both asymptomatic and symptomatic infections ${ }^{5}$. According to some authors, conflicting results could be attributed to some factors such as differences in the studies design, target population, methodology, active exclusion of coinfections with other intestinal pathogens and geographical distribution of assemblages and their variants ${ }^{5,44}$. All the children enrolled in the present survey were asymptomatic so that the attempts made to verify possible association between assemblages and symptoms could not be performed. Even so, it is worth noting that most of the children were also infected by isolates identified as AII. In general, asymptomatic infections are more common even though it is currently unknown whether this lack of symptoms reflects the exposure to low virulent strains, and the ability of the host to keep the infection under control, particularly after multiple exposures ${ }^{44}$. In addition, asymptomatic individuals play a role as carriers, spreading cysts in different environments, including the internal areas of daycare centers in endemic resource-limited settings ${ }^{8}$. Recently, some authors have highlighted that the true clinical impact of endemic pediatric giardiasis remains unclear, even if the evidences led to the fact that infections in children living in high prevalence settings are not associated with clear or persistent symptomatology, raising the possibility that the parasite colonization is protective in these children ${ }^{4}$.

\section{CONCLUSION}

In conclusion, this study provided interesting data on the occurrence and genetic diversity of $G$. duodenalis isolates among children aged less than six years old, attending a daycare center and belonging to low-income families living in an economically successful region. However, it is opportune to point out that the refusal of the daycare center staff to participate in the survey has limited information on the infection among adults in close contact with children, in a collective environment. Even so, the epidemiological information assembled is relevant and reinforces that in settings where there is an adequate sanitary infrastructure, the prevalence rates of intestinal parasites can be reduced, particularly of geohelminths. In turn, infections caused by protozoa such as Giardia still show high rates in children. In this context, situations in which person-to-person transmission is favored, the improvement of basic sanitation conditions must be combined with good hygiene practices, both in daycare centers and in domestic environments.

\section{ACKNOWLEDGMENTS}

We are very grateful to all the individuals for their participation in the study.

\section{CONFLICT OF INTERESTS}

All the authors declare that they have no conflict of interests.

\section{REFERENCES}

1. Feng Y, Xiao L. Zoonotic potential and molecular epidemiology of Giardia species and giardiasis. Clin Microbiol Rev. 2011;24:110-40.

2. Savioli L, Smith H, Thompson A. Giardia and Cryptosporidium join the 'Neglected Diseases Initiative'. Trends Parasitol. 2006;22:203-8.

3. Adam RD. Biology of Giardia lamblia. Clin Microbiol Rev. 2001;14:447-75.

4. Bartelt LA, Patts-Mills JA. Giardia: a pathogen or commensal for children in high prevalence settings? Curr Opin Infect Dis. 2016;29:502-7.

5. Cacciò SM, Lalle M, Staff SG. Host specificity in the Giardia duodenalis species complex. Infect Genet Evol. 2018;66:33545 .

6. Kohli A, Bushen OY, Pinkerton RC, Houpt E, Newman RD, Sears CL, et al. Giardia duodenalis assemblage, clinical presentation and markers of intestinal inflammation in Brazilian children. Trans R Soc Trop Med Hyg. 2008;102:718-25. 
7. Coronato-Nunes B, Pavan MG, Jaeger LH, Monteiro KJ, Xavier SC, Monteiro FA, et al. Spatial and molecular epidemiology of Giardia intestinalis deep in the Amazon, Brazil. Plos One. 2016;11:e0158805.

8. Oliveira-Arbex AP, David EB, Oliveira-Sequeira TC, Bittencourt GN, Guimarães S. Genotyping of Giardia duodenalis isolates in asymptomatic children attending daycare centre: evidence of high risk for anthroponotic transmission. Epidemiol Infect. 2016;144:1418-28.

9. Scalia LA, Fava NM, Soares RM, Limongi JE, Cunha MJ, Pena IF, et al. Multilocus genotyping of Giardia duodenalis in Brazilian children. Trans R Soc Trop Med Hyg. 2016;110:343-9.

10. Sulaiman IM, Fayer R, Bern C, Gilman RH, Trout JM, Schantz PM, Das P, et al. Triosephosphate isomerase gene characterization and potential zoonotic transmission of Giardia duodenalis. Emerg Infect Dis. 2003;9:1444-52.

11. Read CM, Monis PT, Thompson RC. Discrimination of all genotypes of Giardia duodenalis at the glutamate dehydrogenase locus using PCR-RFLP. Infect Genet Evol. 2004;4:125-30.

12. Lalle M, Pozio E, Capelli G, Bruschi F, Crotti D, Cacciò SM. Genetic heterogeneity at the b-giardin locus among human and animal isolates of Giardia duodenalis and identification of potentially zoonotic subgenotypes. Int J Parasitol. 2005;35:207-13.

13. Larkin MA, Blackshields G, Brown NP, Chenna R, McGettigan PA, McWilliam H, et al. Clustal W and Clustal X version 2.0. Bioinformatics. 2007;23:2947-8.

14. Guindon S, Gascuel O. A simple, fast, and accurate algorithm to estimate large phylogenies by maximum likelihood. Syst Biol. 2003;52:696-704.

15. Huelsenbeck JP, Ronquist F, Nielsen R, Bollback JP. Bayesian inference of phylogeny and its impact on evolutionary biology. Science. 2001;294:2310-4.

16. David EB, Guimarães S, Oliveira AP, Oliveira-Sequeira TC, Bittencourt GN, Nardi AR, et al. Molecular characterization of intestinal protozoa in two poor communities in the State of São Paulo, Brazil. Parasit Vectors. 2015;8:103.

17. Rebolla MF, Silva EM, Gomes JF, Falcão AX, Rebolla MV, Franco RM. High prevalence of Blastocystis spp. infection in children and staff members attending public urban schools in São Paulo State, Brazil. Rev Inst Med Trop Sao Paulo. 2016;58:31

18. Turki H, Hamedi Y, Heidari-Hengami M, Najafi-Asl M, Rafati S, Sharifi-Sarasiabi K. Prevalence of intestinal parasitic infection among primary school children in southern Iran. J Parasit Dis. 2017;41:659-65.

19. Kasei R, Carmena D, Jelowdar A, Beiromvard M. Molecular genotyping of Giardia duodenalis in children from Behbahan, southwestern Iran. Parasitol Res. 2018;117:1425-31.

20. Pipiková J, Papajová I, Majláthová V, Soltys J, Bystrianska J, Schusterová I, et al. First report on Giardia duodenalis assemblage F in Slovakian children living in poor environmental conditions. J Microbiol Immunol Infect. 2020;53:148-56.

21. Mekonnen HS, Ekubagewargies DT. Prevalence and factors associated with intestinal parasites among under-five children attending Woreta Health Center, Northwest Ethiopia. BMC Infect Dis. 2019;19:256.

22. Ignacio CF, Silva ME, Handam NB, Alencar MF, Sotero-Martins A, Barata MM, et al. Socioenvironmental conditions and intestinal parasitic infections in Brazilian urban slums: a crosssectional study. Rev Inst Med Trop Sao Paulo. 2017;59:e56.

23. Barbosa CV, Barreto MM, Andrade RJ, Sodré F, d'AvilaLevy CM, Peralta JM, et al. Intestinal parasite infections in a rural community of Rio de Janeiro (Brazil): prevalence and genetic diversity of Blastocystis subtypes. PloS One. 2018;13:e0193860.

24. Faria CP, Zanini GM, Dias GS, Silva S, Freitas MB, Almendra R, et al. Geospatial distribution of intestinal parasitic infections in Rio de Janeiro (Brazil) and its association with social determinants. PloS Negl Trop Dis. 2017;11:e0005445.

25. Seguí R, Muñoz-Antoli C, Klisiowicz DR, Oishi CY, Köster PC, de Lucio A, et al. Prevalence of intestinal parasites, with emphasis on the molecular epidemiology of Giardia duodenalis and Blastocystis sp., in the Paranaguá Bay, Brazil: a community survey. Parasit Vectors. 2018;11:490.

26. Guimarães S, Sogayar MI. Occurrence of Giardia lamblia in children of municipal day care centers from Botucatu, São Paulo State, Brazil. Rev Inst Med Trop Sao Paulo. 1995;37:501-6.

27. Silva RR, Silva CA, Pereira CA, Nicolato RL, Negrão-Corrêa D, Lamounier JA, et al. Association between nutritional status, environmental and socio-economic factors and Giardia lamblia infections among children aged 6-71 months in Brazil. Trans R Soc Trop Med Hyg. 2009;103:512-9.

28. Keystone JS, Krajden S, Warren MR. Person-to-person transmission of Giardia lamblia in day-care nurseries. Can Med Assoc J. 1978;119:241-8.

29. Thompson RC, Ash A. Molecular epidemiology of Giardia and Cryptosporidium infections. Infect Genet Evol. 2016;40:315-23.

30. Lebbad M, Petersson I, Karlsson L, Botero-Kleiven S, Andersson JO, Svenungsson B, et al. Multilocus genotyping of human Giardia isolates suggests limited zoonotic transmission and association between assemblage B and flatulence in children. PLoS Negl Trop Dis. 2011;5:e1262.

31. Scorza AV, Ballweber LR, Tangtrongsup S, Panuska C, Lappin MR. Comparisons of mammalian Giardia duodenalis assemblages based on the $\beta$-giardin, glutamate dehydrogenase and triose phosphate isomerase genes. Vet Parasitol. 2012;189:182-8.

32. Liu A, Yang F, Shen Y, Zhang W, Wang R, Zhao W, et al. Genetic analysis of the Gdh and $\mathrm{Bg}$ genes of animal-derived Giardia duodenalis isolates in Northeastern China and evaluation of zoonotic transmission potential. PloS One. 2014;9:e95291. 
33. Broglia A, Weitzel T, Harms G, Cacció SM, Nöckler K. Molecular typing of Giardia duodenalis isolates from German travellers. Parasitol Res. 2013;112:3449-56.

34. Ryan U, Cacciò SM. Zoonotic potential of Giardia. Int J Parasitol 2013;43:943-56.

35. Souza SL, Gennari SM, Richtzenhain LJ, Pena HF, Funada MR, Cortez A, et al. Molecular identification of Giardia duodenalis isolates from humans, dogs, cats and cattle from the state of São Paulo, Brazil, by sequence analysis of fragments of glutamate dehydrogenase (gdh) coding gene. Vet Parasitol. 2007;149:258-64.

36. Anuar TS, Azreen SN, Salleh FM, Moktar N. Molecular epidemiology of giardiasis among Orang Asli in Malaysia: application of the triosephosphate isomerase gene. BMC Infec Dis. $2014 ; 14: 78$.

37. Damitie M, Mekonnen Z, Getahun T, Santiago D, Leyns L. Molecular epidemiology of Giardia duodenalis infection in humans in Southern Ethiopia: a triosephosphate isomerase gene-targeted analysis. Infect Dis Poverty. 2018;7:17.

38. Santos CK, Grama DF, Limongi JE, Costa FC, Couto TR, Soares RM, et al. Epidemiological, parasitological and molecular aspects of Giardia duodenalis infection in children attending public daycare centers in southeastern Brazil. Trans R Soc Trop Med Hyg. 2012;106:473-9.
39. Mahdy AK, Surin J, Mohd-Adnan A, Wan KL, Lim YA. Molecular characterization of Giardia duodenalis isolated from Semai Pahang Orang Asli (Peninsular Malaysia aborigines). Parasitology. 2009;136:1237-41.

40. Jerez Puebla LE, Núñez FA, Santos LP, Rivero RL, Silva IM, Valdés LA, et al. Molecular analysis of Giardia duodenalis isolates from symptomatic and asymptomatic children from La Habana, Cuba. Parasite Epidemiol Control. 2017;24:105-13.

41. Bartelt LA, Sartor RB. Advances in understanding Giardia: determinants and mechanisms of chronic sequelae. F1000Prime Rep. 2015;7:62.

42. Choy SH, Al-Mekhlafi HM, Mahdy MA, Nasr NN, Sulaiman M, Lim YA, et al. Prevalence and associated risk factors of Giardia infection among indigenous communities in rural Malaysia. Sci Rep. 2014;4:6909.

43. Minetti C, Taweenan W, Hogg R, Featherstone C, Randle N, Latham SM, et al. Occurrence and diversity of Giardia duodenalis assemblages in livestock in the UK. Transbound Emerg Dis. 2014;61:e60-7.

44. Certad G, Viscogliosi E, Chabé M, Cacciò SM. Pathogenic mechanisms of Cryptosporidium and Giardia. Trends Parasitol. 2017;33:561-76. 